\title{
Study of Dielectric Properties of Aqueous Solution of Nicotinic Acid Using Time Domain Technique
}

\author{
S. D. Pawar ${ }^{1}$, S. K. Popalghat ${ }^{2}$ \\ ${ }^{2}$ Physics Research Centre, Post Graduate Department of Physics, J. E. S. College Jalna-431203; Maharashtra (India)
}

\begin{abstract}
The present paper represents, the work undertaken of the study of dielectric constant of aqueous solution of Nicotinic acid for various concentrations. The time domain reflectometry techniques used for the study in the frequency range from $10 \mathrm{MHz}$ to $30 \mathrm{GHz}$. The relaxation time $(\tau)$, The static dielectric constant $\left(\varepsilon_{0}\right)$, dielectric constant at higher frequency $\left(\varepsilon_{\infty}\right)$ and thermodynamic parameters of mixture of Nicotinic acid with water have evaluated at $25^{\circ} \mathrm{c}$ temperatures. The thermodynamic parameters of mixed solvent such as the enthalpy of activation $(\Delta H)$ and entropy of activation $(\Delta S)$ are also evaluated.
\end{abstract}

Keywords: Alkaloids, Dielectric constant, TDR, Relaxation time, Thermodynamic parameter.

\section{Introduction}

Nicotinic acid (Niacin) is a alkaloid of pyridine type. It is found in variety of foods like chicken, fish cereal, liver etc. It also created by synthesized from tryptophan. If need of Nicotinic acid, we can get from Amino acid which exist in most of the forms of protein. It also involved in both DNA repair and the production of steroid hormones in the adrenal gland. It is colorless solid, soluble in water. Nicotinic acid used to lower cholesterol, Triglycerides (types of fat) and treat coronary artery disease. Its molecular formula is $\mathrm{C}_{6} \mathrm{H}_{5} \mathrm{NO}_{2}$ and molecular structure is shown in follow [ 1].<smiles>O=C(O)c1cccnc1</smiles>

Molecular structure of Nicotinic acid

Very few researcher have worked on an Nicotinic acid in various field. Hence we have chosen the Nicotinic acid for study. The dielectric properties of nicotinic acid with water at various concentrations at $25^{\circ} \mathrm{C}$ is studied using Time Domain Reflectometry Technique in frequency range 10 $\mathrm{MHz}$ to $30 \mathrm{GHz}$. The dielectric behavior of this solution is explained by Cole-Devidson model. The dielectric constant, dielectric loss, activation enthalpy and activation entropy are evaluated. he dielectric constant is one of the important physiochemical properties of the mixed solvent, which enhance most of the biological, pharmaceutical, chemical, physical, analytical laboratory applications etc. [2,3].

\section{Experimental Method}

A) Materials: Nicotinic acid 99\% was obtained commercially from Anand Agency, Pune, made by Sisco
Research laboratories Pvt. Ltd. India. The solution was prepared by mixing the nicotinic acid with water.

B) Measurements: The dielectric constants and relaxation time of various mixtures of solutions was measured by TDR, the Tektronix model No. DSA8200 digital serial analyzer sampling mainframe along with the sampling module 80E08.TDR dielectric measurement systems consist of step generator, which is produce fast rising pulse of the order of picoseconds. A train of suitable fast rising pulses is applied to a transmission line usually a co-axial line with characteristic impedance $50 \Omega$.A co-axial line is connected to sampling device (sample holder), the systematic block diagram of the experimental set up for TDR is shown in Figure1.(a)and(b).A suitable fast rising pulse $R_{1}(t)$ is applied to a transmission line and incident to the sample under study and its reflected part $\mathrm{R}_{\mathrm{X}}(\mathrm{t})$ from the sample solution in the sample holder is shown in figure (2) $[4,8]$.

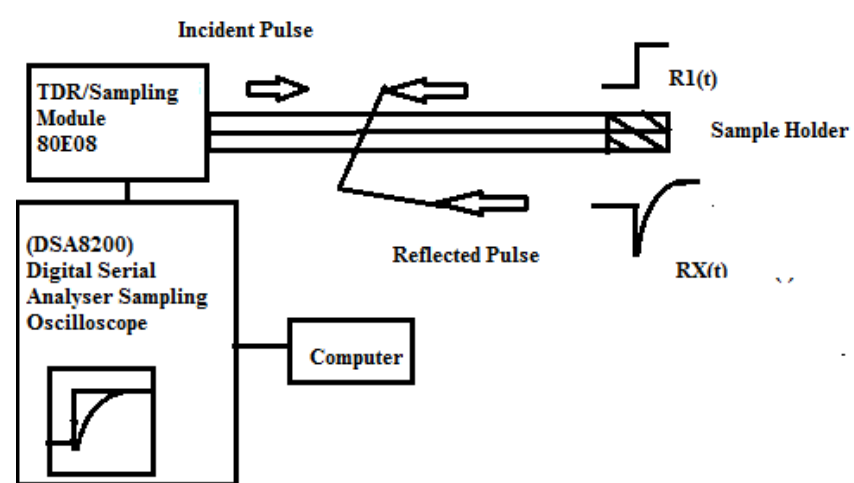

Figure 1: a) Systematic Block Diagram of Time Domain Reflectometry 
International Journal of Science and Research (IJSR)

ISSN (Online): 2319-7064

Index Copernicus Value (2013): 6.14 | Impact Factor (2014): 5.611

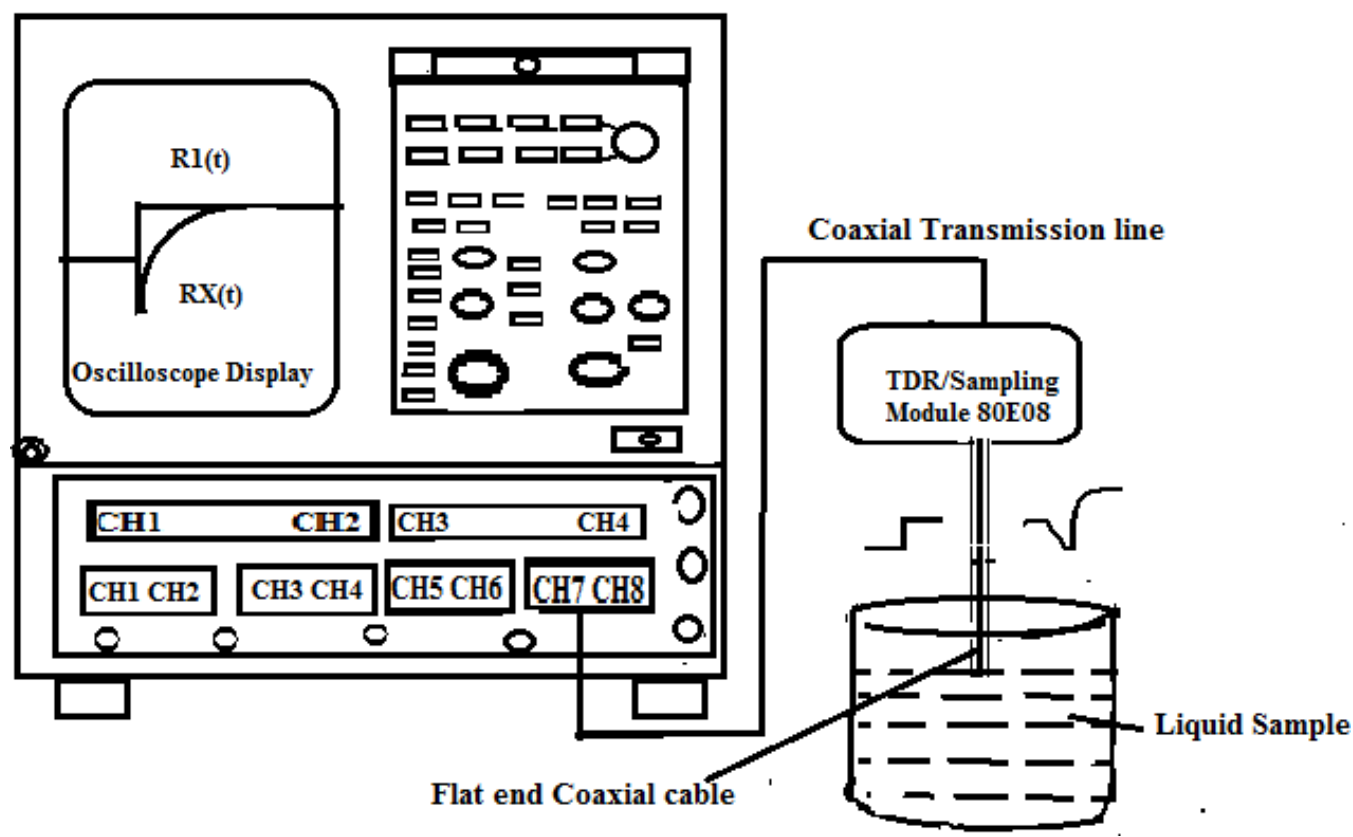

Figure 1: b) Experimental Setup of Time Domain Reflectometry Technique.

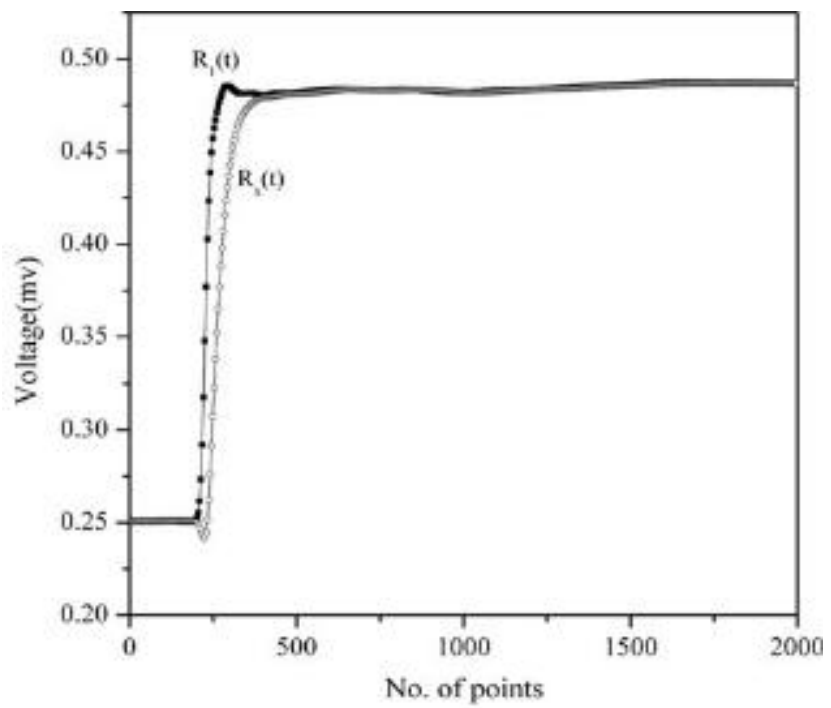

Figure 2: Reflected pulses without sample $R_{1}(t)$ and with sample $R_{X}(t)$

Table 1: Dielectric parameter of nicotinic acid mixture At $25^{\circ} \mathrm{C}$

\begin{tabular}{|c|c|c|c|c|}
\hline Conc. & $\varepsilon_{0}$ & $\tau(\mathrm{PS})$ & $\varepsilon_{\infty}$ & $\beta$ \\
\hline 0.01 & 81.42 & 8.69 & 2.00 & 0.946 \\
\hline 0.02 & 81.07 & 8.41 & 2.00 & 0.934 \\
\hline 0.03 & 80.28 & 8.34 & 2.00 & 0.922 \\
\hline
\end{tabular}

Table 2: Thermodynamic parameter for Nicotinic acid

\begin{tabular}{|c|c|c|}
\hline Conc. & $\begin{array}{c}\left.\Delta \mathrm{H}_{(\mathrm{KJ} \mathrm{mol}}^{-1}\right) \\
\text { Enthalpy }\end{array}$ & $\begin{array}{c}\Delta \mathrm{S}\left(\mathrm{J} \mathrm{mol}^{-1} \mathrm{~K}^{-1}\right) \\
\text { Entropy }\end{array}$ \\
\hline 0.01 & 4.01 & 0.19 \\
\hline 0.02 & 3.76 & 0.15 \\
\hline 0.03 & 3.09 & 0.12 \\
\hline
\end{tabular}

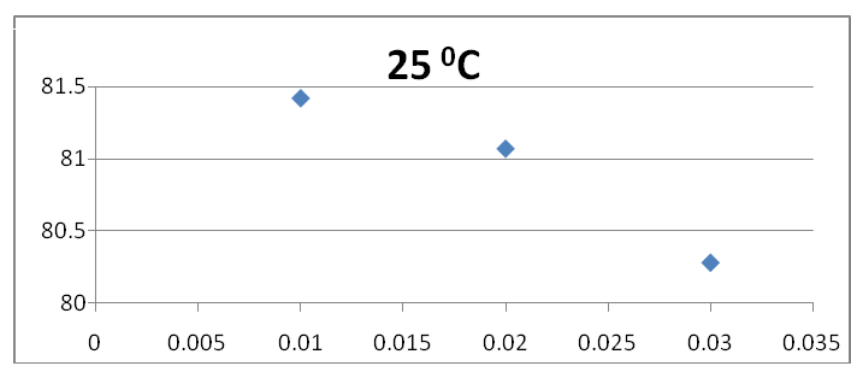

Figure 3: Variation of state dielectric constant $\left(\varepsilon_{\square}\right) \_$with variation of concentration of Nicotinic acid mixture and temperature.

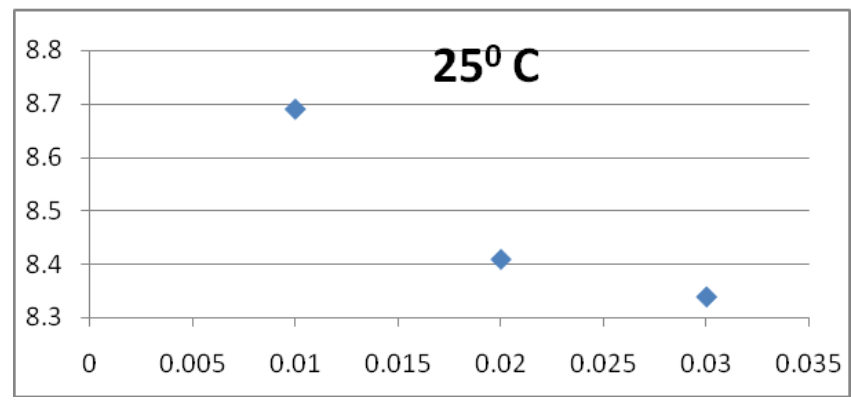

Figure 4: Variation of relaxation time with variation of concentration of Nicotinic acid mixture and temperature.

\section{Result and Discussion}

The recorded pulses are added $\left[\mathrm{q}(\mathrm{t})=\mathrm{R}_{1}(\mathrm{t})+\mathrm{Rx}(\mathrm{t})\right]$ and subtracted $\left[p \quad(t)=R_{1}(t)-\quad R x(t)\right]$.Further the Fourier transformation of $p(t)$ and $q(t)$ was obtained by Summation and Samulon method for the frequency range $10 \mathrm{MHz}$ to 30 $\mathrm{GHz}$. The complex reflection spectra were determined as follows.[10]

Where $\mathrm{p}(\omega)$ and $\mathrm{q}(\omega)$ are Fourier transformation of $\mathrm{p}(\mathrm{t})$ and $q(t)$ respectively, cis speed of light, $\omega$ is the ${ }^{-}$angular frequency, $d$ is effective length and $j=\sqrt{ } 1$ 


\section{International Journal of Science and Research (IJSR) \\ ISSN (Online): 2319-7064 \\ Index Copernicus Value (2013): 6.14 | Impact Factor (2014): 5.611}

The complex permittivity spectrum of the Nicotinic acid mixtures solution is an asymmetric shape and it is determined by the Harviliak - Negami (HN) equation [11]. The complex dielectric permittivity data were fitted to $\mathrm{HN}$ model using non - linear least square fit method in order to extract dielectric relaxation time with the following expression $[6,11]$.

$$
\varepsilon^{*}(\omega)=\varepsilon_{\infty}+\frac{\left(\varepsilon_{0}-\varepsilon_{\infty}\right)}{\left[1+(j \omega \tau)^{1-\alpha}\right]^{\beta}}
$$

Where $\varepsilon_{0}$ is the static dielectric constant, $\varepsilon_{\infty}$ is the dielectric constantan high frequency. $\tau$ is relaxation time, the $\alpha \& \beta$ are symmetric and asymmetric distribution of relaxation time respectively. The Havriliak- Negami equation includes the relaxation model as a limiting form.

1) If $\alpha=0$ and $\beta=1$ then single Debye equation.

2) $0<=\alpha<=1$ then it would be Cole - Cole model of symmetric distribution of relaxation times.

3) $\alpha=0$ and $\beta$ varied such that $0<=\beta<=1$ this behavior is identified as Cole Davidson (CD) asymmetric distribution of relaxation time.

The value of static dielectric constant $\left(\varepsilon_{0}\right)$, dielectric relaxation time $(\tau)$ and dielectric constant high frequency $\left(\varepsilon_{\infty}\right)$ are reported in table -1 for Nicotinic acid-water mixture. The relaxation time observed to decreases systematically as increase in concentration.

With the increase in concentration of solution the decrease in dielectric constant and systematic change in the dielectric parameters of the solution can be explain on the basis of molecular interaction. The decrease in $\tau$ values with increase concentration is indicating that number of dipoles decrease in solution. The intermediate structure formed rotates fast there by giving the decrease value of $\tau$ in solution.

The thermodynamic parameters of Nicotinic acid-water mixture solution are evaluated using Eyeing equation as follows.

$\tau=(\mathrm{h} / \mathrm{KT}) \exp (\Delta \mathrm{H} / \mathrm{RT}) \exp (-\Delta \mathrm{S} / \mathrm{R})$

Where $\Delta \mathrm{S}$ is the entropy of activation. $\Delta \mathrm{H}$ is the enthalpy of activation in $\mathrm{KJ} / \mathrm{mol}$. $\tau$ is the relaxation time in Ps. $\mathrm{K}$ is Boltzmann's constant and $\mathrm{T}$ is the temperature in Kelvin scale and $\mathrm{h}$ is the Planck's constant the result in values of activation energy are obtained by least square fit method are reported in table (3). Activation energy for entire concentrations is positive; this indicates that it is an endothermic reaction. As concentration is added in water the corresponding activation energy falls, showing that it's less energy requirement for rotation than hydrogen bond in water.

\section{Conclusion}

The dielectric properties of Nicotinic acid-water mixture have studied using time domain reflectometry technique in the frequency range $10 \mathrm{MHz}$ to $30 \mathrm{GHz}$ at250Ctemperature and various concentrations. The deviation in dielectric constant and relaxation times from ideality may be due to interaction in Nicotinic acid - water mixture dielectric constant and relaxation time goes on decreasing as concentration increases.

Also thermodynamic parameters enthalpy and entropy of activation of Nicotinic acid - water mixture decreases as concentration is increases.

From the observed result we can conclude that dielectric constant, relaxation time, enthalpy and entropy of Nicotinic acid- water mixture are depending on concentration.

\section{Acknowledgement}

Authors are thankful to School of Physical Science, Swami Ramanand Teerth Marathawada University Nanded (M.S.) for availing the laboratory facility, Authors are also thankful to principal J.E.S. College Jalna and DST for enhancing laboratory facilities under FIST program.

\section{References}

[1] Http://enWivikipedia.org/Wiki/niacin,

[2] S.X.Wang, Z.C.Tan, Y.Y.Dif,Xu,M.H.Wang,L.X.SunandT.Zhang J. of thermal analyser and vol. 76 (2004) 335,342.

[3] J. B. Hasted Aqueous dielectric (Champman and Hill London) 1973.

[4] G.R. Mahajan and A.C. Kumbharkhane Int. J. of Bioses Bioche. And Bioform Vol 2, No.2, March 2012.66, 793802.

[5] A.D. Vyas, V.A. Rana and D.S. Gadani Ind. J of Pure and App. Phys Vol 49.April 2011, 277-283.

[6] M.N. Shinde, R.B. Talware, P.G. Hudge, Y.S. Joshi and A.C. Kumbharkhane pra. J. of Physics vol.78, No. 2 Feb. 20/12 PP. 297-308.

[7] P.G. Hudge, M.P. Lokhande and A.C. Kumbharkhane, Ind J. Phys (Sept. 2012) 86(9)813-818.

[8] C.S. Mali, S. D. Cchavan,K. S. Kanse A. C. Kumbharkhane and S. C. Mehrotra; Indian J. of Pure \& App. Physics Vol 45, May 2007, pp. 476-481.

[9] Y.S. Joshi, A.C. Kumbharkhane J. Mol. Liq 161 (2011) $120-124$

[10]M. B Swami , V.P.Pawar, P.G.Hudge,A.C.Kumbrkhane.pro.NCMTA.-2013,178185

[11]Havriliak S. Negami S.J. Polym. Sci. (1966)14, 99-117. 